$$
\begin{aligned}
& \text { مدلسازى غيرخطى درام - بويلر نيرو گاه سيكل تر كيبى كرمان و كنترل سطح درام به ويزه در } \\
& \text { شر ايط تريتٍ } \\
& \text { محمد مقصودى'، ابراهيم سالارى زاده '، مليحه مغفورى }
\end{aligned}
$$

'

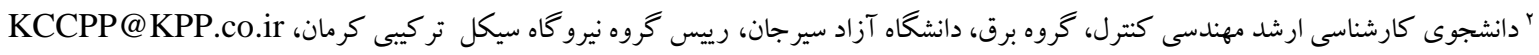

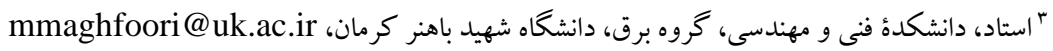

كلمات كليدى: كنترل سطح درام بويلر، نيرو كاه سيكل تر كيبى كرمان، كنترل سرى (جهار المانه)، كنترل كنده PID

\title{
Nonlinear Modelling of Kerman Combined Cycle Power Plant Drum- Boiler and Drum Level control especially in trip conditions
}

\author{
Mohammad Maghsoudi, Ebrahim Salarizadeh, Malihe Maghfoori
}

\begin{abstract}
There are various methods of power generation such as combined cycle power plants. There are many variables in a power plant boiler unit, but the most important variables are Pressure and specially drum level that control system should be put it in the safe range. The purpose of this article is, modifying the oscillatory behavior of the drum level of Kerman combined cycle power plant and especially control of drum level in trip conditions. At first in this article, high pressure drum boiler of Kerman combined cycle power plant is modeled and analyzed. Then drum level control logic of power plant is analyzed and modifications are being made to improve this logic and the results are compared in practice. In the new logic, a control loop (PI) is used for the error signal of the output steam and the input water to the drum and a control loop (PID) for the level error signal and for more accurate estimation, limiting the drum input water and protective conditions, drum pressure signal is used. In fact the new logic is cascade control by measuring four elements for estimating the input water to the drum. The results show that the new logic reduces the Kerman power plant drum boiler level oscillations and keeps the drum level in the safe range very well in trip conditions.
\end{abstract}

Keywords: drum boiler level control, Kerman Combined Cycle Power Plants, cascade control (four element), PID controller 
اما كنترل تكك المانه نمى تواند در شرايط كارى مختلف سطح درام را بهخوبى كنترل نمايد.

در منطق فعلى نيرو گاه كرمان از يك كنترل كننده براى كنترل سطح درام استفاده مى شود و اين موضوع باعث ايجاد نوسان در سطح

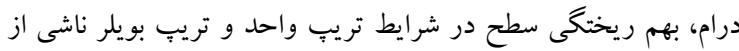
سطح در شرايط بحرانى مى شود. در اين مقاله مدل غير خطى درام بويلر

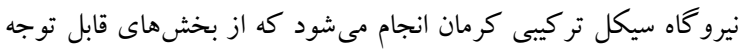

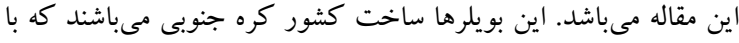

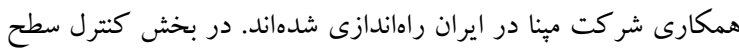
درام نيز از دو حلقه كنترل داخلى و خارجى بهطور سرى بـ با اندازه كيرى

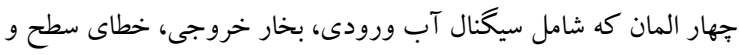
فشار درام براى تخمين دقيق آب ورودى به درام جهت اصلاح سطح

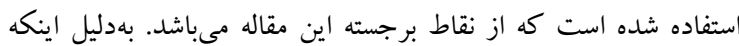

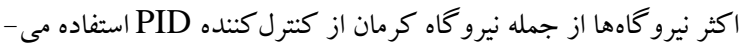

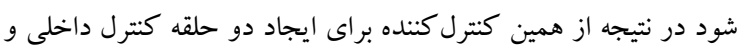

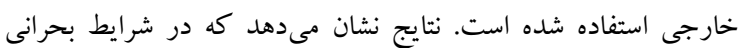

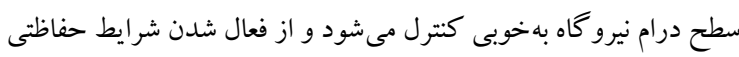
و تريب ناشى از نوسان شديد سطح جلو گيرى مى شود و همبحنين در برد

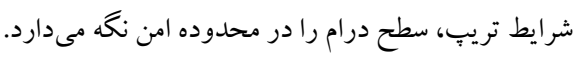

\section{r- نيروكاه كرمان}

شكل (1) نيرو گاه سيكل تركيبى كرمان را نشان مىدهد. نيرو كاه

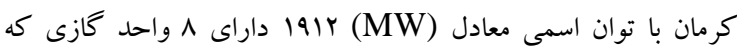
هر كدام با توان اسمى (MW) 109 و F و واحد بخار كه هر كدام با توان

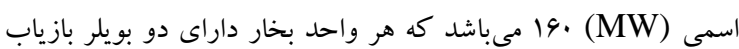

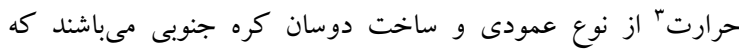

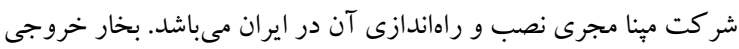

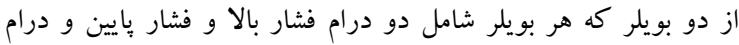

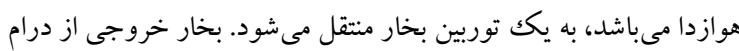

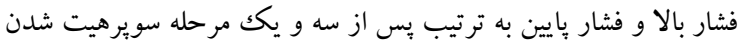

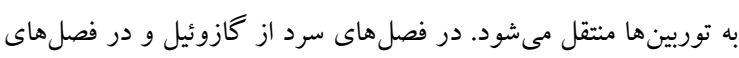

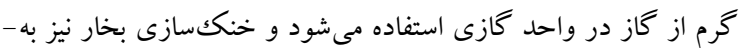

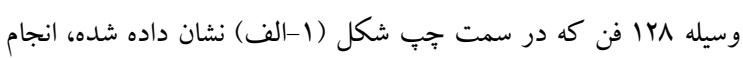

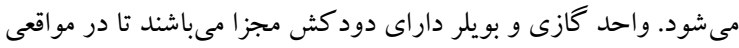

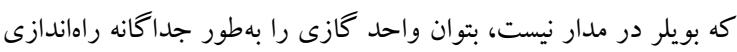

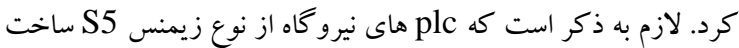

$$
\text { كشور آلمان مىباشند. }
$$

1 - مقلمه

با توجه به رشد زياد صنايع در زمينهاى مختلف و افزايش

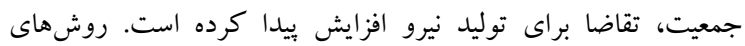

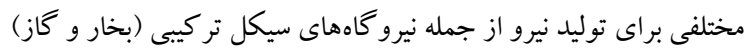

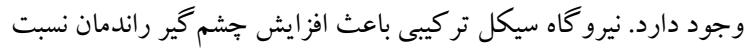

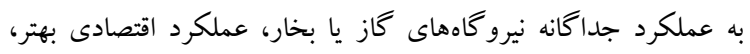

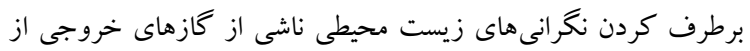

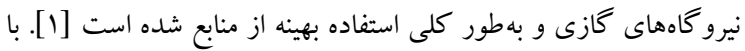
توجه به افزايش و كاهش سريع بار در شبكه سراسرى، لازم است كه وله

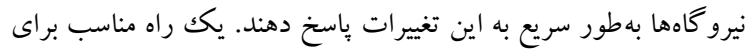

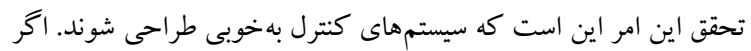

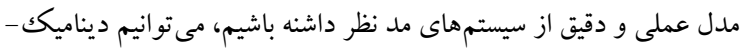

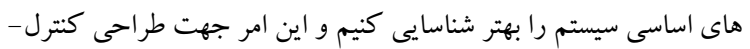
كننده به مهندسين كمكك شايانى مى كند. در [1] مدل غير خطى و و كاملاً

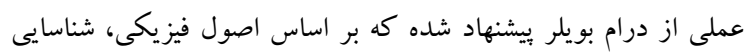

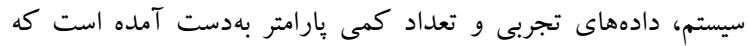
مربوط به دادههاى فيزيكى درام بويلر مىباشند. در [r] از مدل [1]

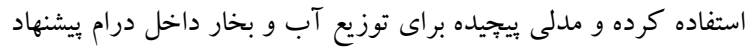

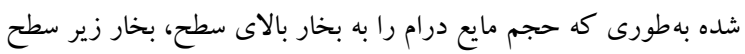

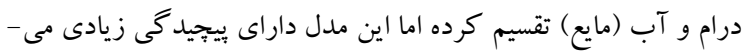

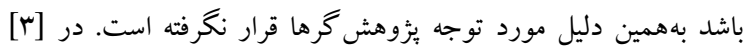

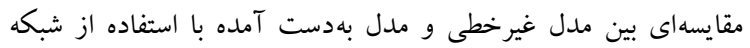
عصبى انجام شده و نتايج نشان داده كه در شرايط غير نرمال مدل

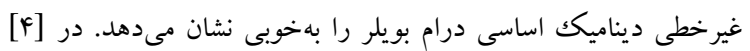
مدل غيرخطى براى بويلر يكك بار گذر بيشنهاد شده است اما بويلر نيرو گاه كرمان از نوع درامدار و بازيافت عمودى مي بر باشد. در [ه] براى كنترل سطح درام از كنترل مد لغزشى استفاده شدهو نتايج با كنترل با روش م H مقايسه شده است. در [4] از منطق فازى براى

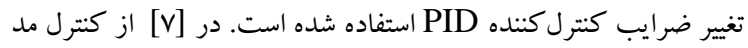

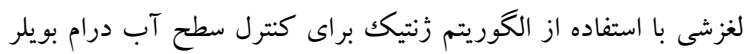

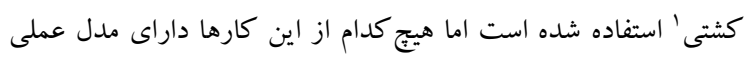

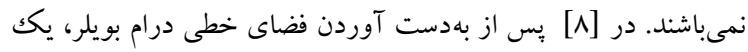

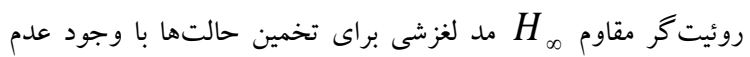

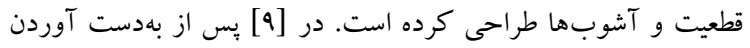
فضاى خطى مدل از كنترل مد لغزشى مرتبه دو براى كنترل سطح درام

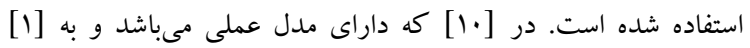

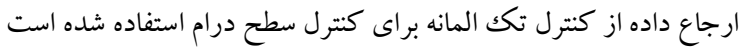




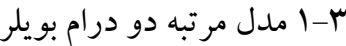

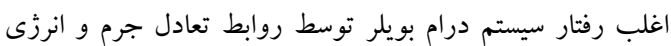

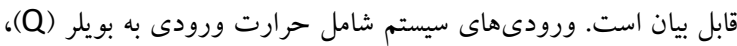

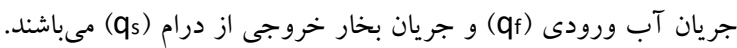

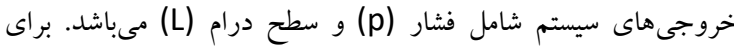

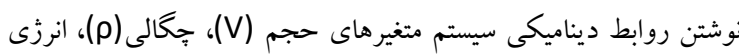

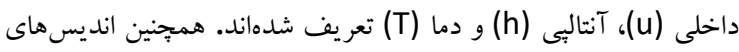

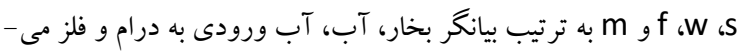

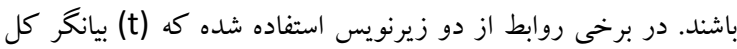

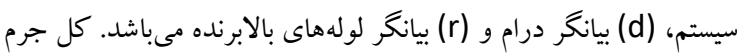

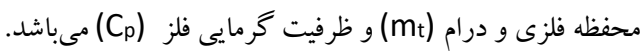
موازنه جرم كلى سيستم با معادله زير بيان مى شود:

$\frac{d}{d t}\left[\rho_{s} V_{s t}+\rho_{w} V_{w t}\right]=q_{f}-q_{s}$ موازنه انرزى كلى سيستم با معادله زير بيان مىشود:

$\frac{d}{d t}\left[\rho_{s} u_{s} V_{s t}+\rho_{w} u_{w} V_{w t}+m_{t} C_{p} t_{m}\right]$

$=Q+q_{f} h_{f}-q_{s} h_{s}$

از آنجايى كه انرزى درونى $u=h-\frac{p}{\rho}$ موازنه انرزى كلى برابر است با: - م

$\frac{d}{d t}\left[\rho_{s} h_{s} V_{s t}+\rho_{w} h_{w} V_{w t}-p V_{t}+m_{t} C_{p} t_{m}\right]$ $=Q+q_{f} h_{f}-q_{s} h_{s}$

جايى كه (V) و (V) $\left(V_{\text {st }}\right)$ سيستم مىباشند. حجم كل سيستم برابر با (Vt) است.

$V_{t}=V_{s t}+V_{w t}$

با تركيب معادلههاى (1)، (r) و (F) مدل مرتبه دو سيستم با معادله

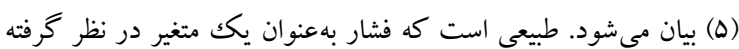

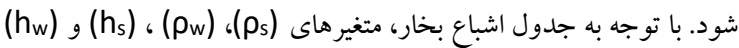

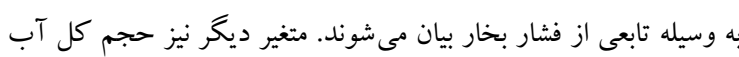

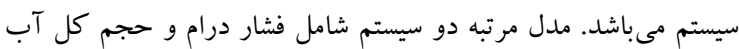
سيستم با معادله زير بيان مىشود: مئس مرنه $e_{21} \frac{d V_{w t}}{d t}+e_{22} \frac{d p}{d t}=Q+q_{f} h_{f}-q_{s} h_{s}$ $e_{11} \frac{d V_{w t}}{d t}+e_{12} \frac{d p}{d t}=q_{f}-q_{s}$
شكل (1-ب) حلقه درام بويلر گردش طبيعى' را نشان مىدهد. آب از مخزن ذخيره وارد درام مىشود و از لولههاى بإيينرونده يايين

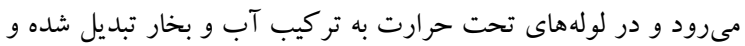
سيس از لولههاى بالابرنده وارد درام مىشود. بخار از سطح درام خارج

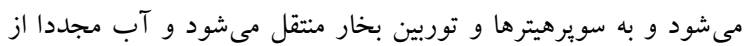

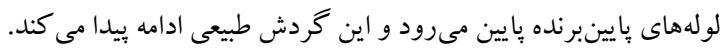

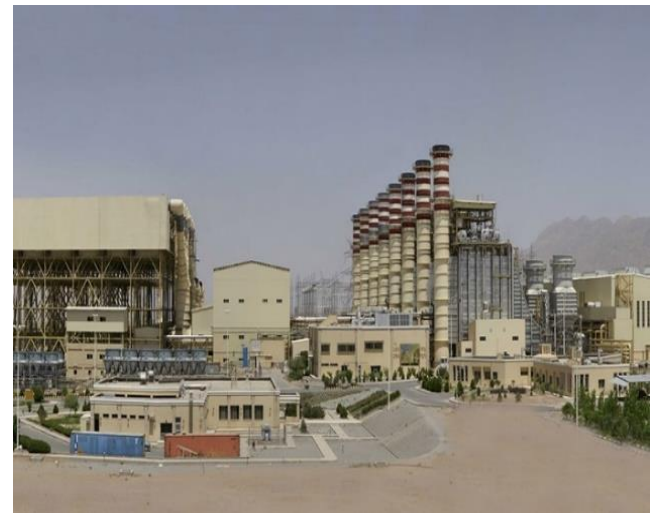

شكل 1- الف: واحد كازى، بويلر و خنكك كندگى

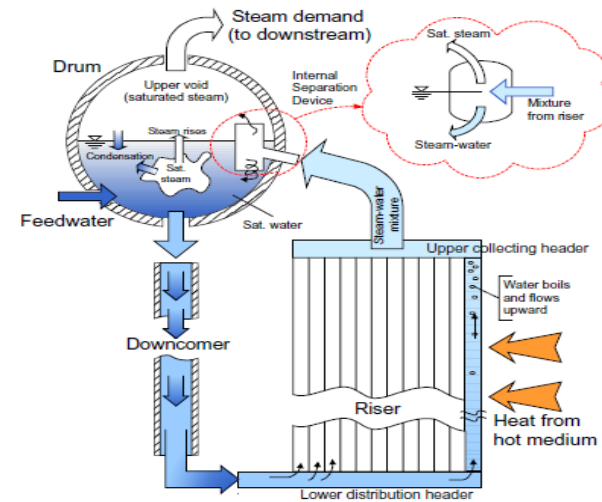

شكل 1-ب: حلقه درام-بويلر كردش طبيعى شكل ا: نيرو گاه سيكل تر كيبى كرمان

\section{r- مدلسازى درام-بويلر}

در [1] مدل غيرخطى براى درام بويلر ييشنهاد شده است. مدلهاى

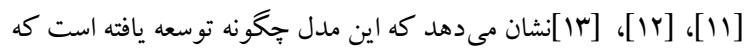

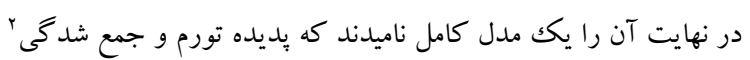

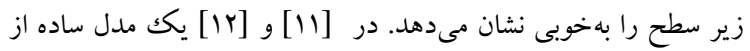

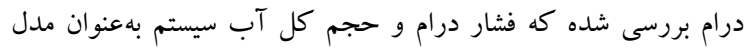

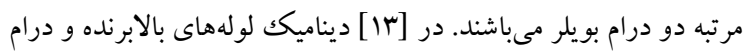
نيز به مدل افزوده شده است كه در واقع مدل مرتبه سه و جهار درام مى - ماسل

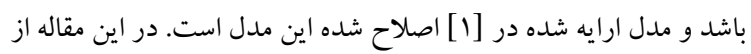

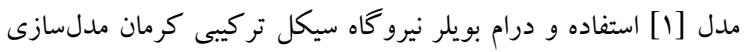
شده است. 


$$
q_{d c}^{2}=\frac{2 \rho_{w} A_{d c}\left(\rho_{w}-\rho_{S}\right) \mathrm{g} \bar{\alpha}_{V} V_{r}}{k}
$$

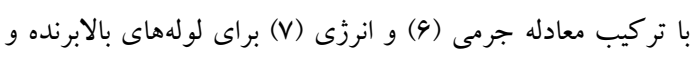

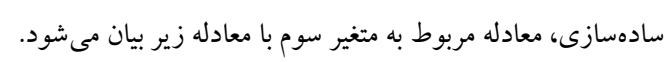
$e_{32} \frac{d p}{d t}+e_{33} \frac{d a_{r}}{d t}=Q+a_{r} h_{c} q_{d c}$

كه در آن ضرايب بهصورت زير تعريف مىشوند. $e_{32}=\left(\rho_{w} \frac{\partial h_{w}}{\partial p}+\alpha_{r} h_{c} \frac{\partial \rho_{w}}{\partial p}\right)\left(1-\bar{\alpha}_{V}\right) V_{r}$

$$
+\left(\left(1-\alpha_{r}\right) h_{c} \frac{\partial \rho_{s}}{\partial p}+\rho_{s} \frac{\partial h_{s}}{\partial p}\right) \bar{\alpha}_{V} V_{r}
$$$$
+\left(\rho_{s}+\left(\rho_{W}-\rho_{s}\right) \alpha_{r}\right) h_{c} V_{r} \frac{\partial \bar{\alpha}_{V}}{\partial p}
$$

$$
-V_{r}+m_{r} C_{p} \frac{\partial t_{s}}{\partial p}
$$

$e_{33}=\left(\left(1-\alpha_{r}\right) \rho_{s}+\alpha_{r} \rho_{W}\right) h_{c} V_{r} \frac{\partial \bar{\alpha}_{V}}{\partial \alpha_{r}}$

جريان جرمى در لولههاى بالابرنده نيز با استفاده از موازنه جرم و

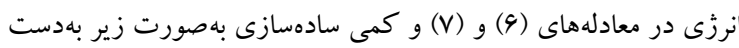

$$
\begin{aligned}
q_{r} & =q_{d c}-V_{r}\left(\bar{\alpha}_{v} \frac{\partial \rho_{s}}{\partial p}+\left(1-\bar{a}_{v}\right) \frac{\partial \rho_{s}}{\partial p}+\left(\rho_{w}-\rho_{s}\right) \frac{\partial \bar{\alpha}_{v}}{\partial p}\right) \frac{d p}{d t} \\
& +\left(\rho_{w}-\rho_{s}\right) V_{r} \frac{\partial \bar{\alpha}_{v}}{\partial \alpha_{r}} \frac{d \alpha_{r}}{d t}
\end{aligned}
$$

\section{ب-r-r مدل مر تبه جهار درام بويلر}

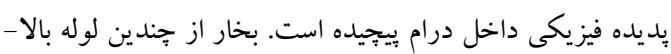

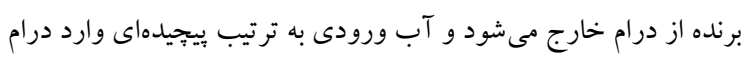

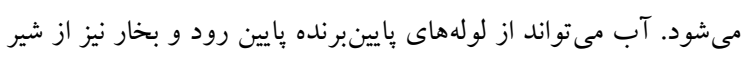

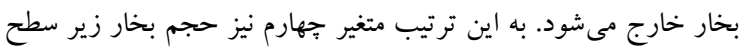

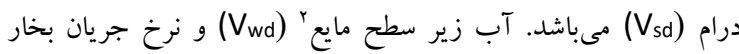

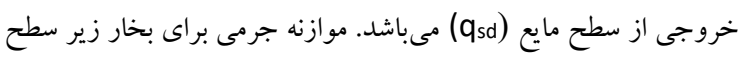

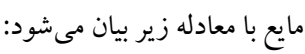

$\frac{d}{d t}\left(\rho_{s} V_{s d}\right)=\alpha_{r} q_{r}-q_{s d}-q_{c d}$

جريان كندانس داخل درام (qcd) مىباشد كه بهصورت زير بيان $q_{c d}=\frac{h_{w}-h_{f w}}{h_{c}} q_{f}+\frac{1}{h_{c}}\left(\begin{array}{l}\rho_{s} V_{s d} \frac{\partial h_{s}}{\partial_{p}}+\rho_{w} V_{w d} \frac{\partial h_{w}}{\partial_{p}} \\ \left(-V_{s d}+V_{w d} \frac{d p}{d t}+m_{d} C_{p} \frac{\partial t_{s}}{\partial_{p}}\right.\end{array}\right)$

$$
\text { كه در آن ضرايب نيز بهصورت زير تعريف مىشوند. }
$$

$e_{11}=\rho_{w}-\rho_{s}$

$e_{12}=V_{w t} \frac{\partial \rho_{w}}{\partial p}+V_{s t} \frac{\partial \rho_{s}}{\partial p}$

$e_{21}=\rho_{w} h_{w}-\rho_{s} h_{s}$

$e_{22}=V_{w t}\left(h_{w} \frac{\partial \rho_{w}}{\partial p}+\rho_{w} \frac{\partial h_{w}}{\partial p}\right)$

$$
\begin{aligned}
& +V_{s t}\left(h_{s} \frac{\partial \rho_{s}}{\partial p}+\rho_{s} \frac{\partial h_{s}}{\partial p}\right) \\
& -V_{t}+m_{t} C_{p} \frac{\partial t_{s}}{\partial p}
\end{aligned}
$$

r-Y مدل مر تبه سه درام بويلر

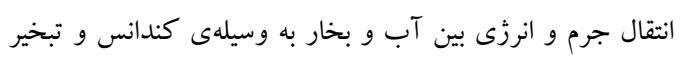

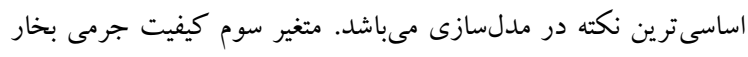

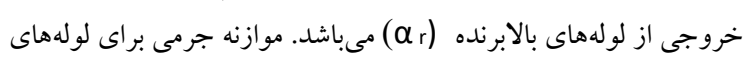

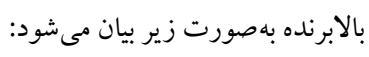

$\frac{d}{d t}\left(\bar{\alpha}_{V} \rho_{s} V_{r}+\rho_{w}\left(1-\bar{\alpha}_{V}\right) V_{r}\right)=q_{d c}-q_{r}$

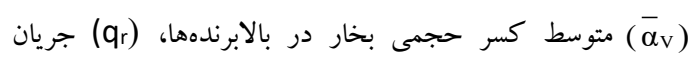

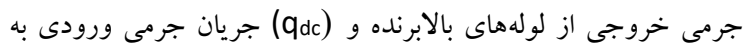

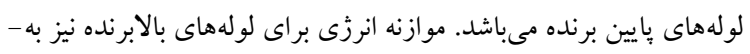
صورت زير تعريف مى شود:

$\frac{d}{d t}\left(\rho_{s} h_{s} \bar{\alpha}_{v} V_{r}+\rho_{w} h_{w}\left(1-\bar{a}_{v}\right) V_{r}-p V_{r}+m_{r} C_{p} t_{s}\right)$ $=Q+q_{d c} h_{w}-\left(\alpha_{r} \mathrm{~h}_{c}+\mathrm{h}_{w}\right) q_{r}$

براى گردش اجبارى' ميزان جريان لولههاى بايينبرنده متغير قابل

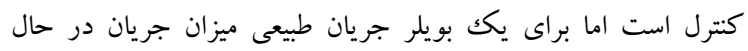

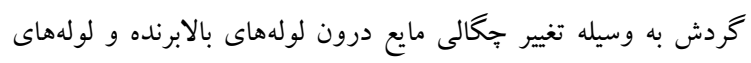

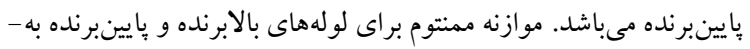
صورت زير تعرف مىشود: $\left(L_{r}+L_{d c}\right) \frac{d q_{d c}}{d t}=\left(\rho_{w}-\rho_{s}\right) \bar{\alpha}_{v} V_{r} g-\frac{k}{2} \frac{q_{d c}^{2}}{\rho_{w} A_{d c}}$ كه در اين معادله (k) ضريب اصطكاكك ابعاد، ( هاى بالابرنده و وايينبرنده و ( است. جريان جرمى در گردش با معادله زير بيان مىشود: 
$e_{21} \frac{d V_{w t}}{d t}+e_{22} \frac{d p}{d t}=Q+q_{f} h_{f}-q_{s} h_{s}$

$e_{32} \frac{d p}{d t}+e_{33} \frac{d a_{r}}{d t}=Q+a_{r} h_{c} q_{d c}$

$e_{42} \frac{d p}{d t}+e_{43} \frac{d \alpha_{r}}{d t}+e_{44} \frac{d V_{s d}}{d t}=\frac{\rho_{s}}{T_{d}}\left(V_{s d}^{0}-V_{s d}\right)+\frac{h_{f}-h_{w}}{h_{c}} q_{f}$

براى تعريف خواص ترموديناميكى آب از برنامه (XSTEAM) كه خواص ترموديناميكى آب بر اساس استاندارد (IAPWS IF-97) تعر يف شده، استفاده شده است. اين كدها از سايت (MATH WORK) قابل دانلود مىباشند.

\section{r-ه شرايط اوليه سيستم}

يكك راه مناسب براى بيدا كردن مقادير اوليه شرايط كارى سيستم

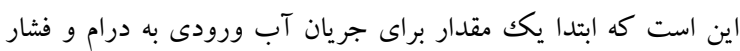

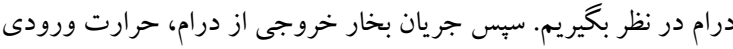

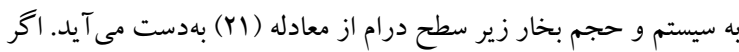
معادله (Y) برقرار باشد، سيستم هميشه در حالت تعادل خو اهد بود دود.

$q_{f}=q_{s}$

$Q=q_{s} h_{s}-q_{f} h_{f w}$

$Q=q_{d c} \alpha_{r} h_{c}$

$V_{s d}=V_{s d}^{0}-\frac{T_{d}\left(h_{w}-h_{f}\right)}{\rho_{s} h_{c}} q_{f}$

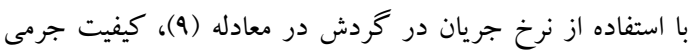

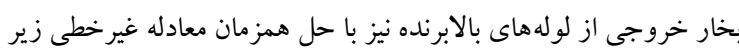
بهدست مى آيد.

$$
\begin{aligned}
& Q=\alpha h_{c} \sqrt{\frac{2 \rho_{w} A_{d c}\left(\rho_{w}-\rho_{S}\right) \mathrm{g} \bar{\alpha}_{V} V_{r}}{k}} \\
& \bar{\alpha}_{v}=\frac{\rho_{W}}{\rho_{W}-\rho_{s}}\left(1-\frac{\rho_{s}}{\left(\rho_{W}-\rho_{s}\right) \alpha_{r}} \ln \left(1+\frac{\rho_{W}-\rho_{s}}{\rho_{s}} \alpha_{r}\right)\right)
\end{aligned}
$$

معادله (Yr) نسبت حجمى بخار (

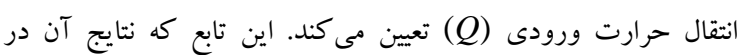

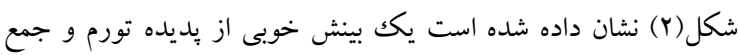
شدگى را به ما نشان مى دهد.

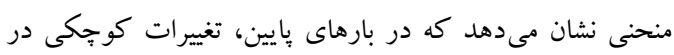

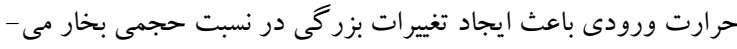

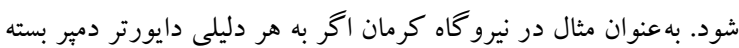

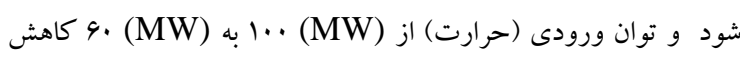

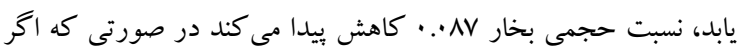

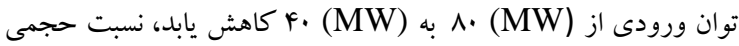

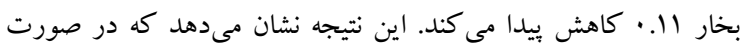

بخار خروجى از سطح مايع نيز به وسيله اختلاف جَّالى آب و بخار و ممنتوم جريان ورودى به درام بهصورت زير استخر اج مى شود:

$q_{s d}=\frac{\rho_{s}}{T_{d}}\left(\mathrm{~V}_{s d}-V_{s d}^{0}\right)+\alpha_{r} q_{d c}+\alpha_{r} \beta\left(q_{d c}-q_{r}\right)$

كه (V) نشان دهنده حجم بخار داخل درام در شرايط فرضى' كه

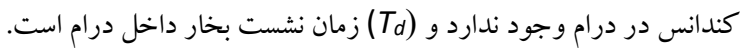
حجم آب داخل درام نيز به صورت زير بهدست مى دآيد:

$V_{w d}=V_{w t}-V_{d c}-\left(1-\bar{\alpha}_{v}\right) V_{r}$

درام يكك هندسه خاصى دارد و رفتار خطى را مىتوان با سطح

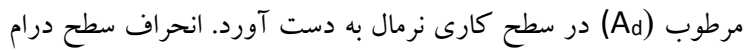
از عملكرد نرمال درام استخر اج مى شود كه بهصورت زير بيان مى شود:

$l=\frac{V_{W d}+V_{S d}}{A_{d}}, l_{w}=\frac{V_{w d}}{A_{d}}, l_{s}=\frac{V_{s d}}{A_{d}}$

با موازنه جرمى بخار زير سطح در معادله (II) و با تركيب معادله-

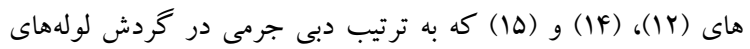
بالابرنده، نرخ كندانس داخل درام و نرخ بخار خروجى از سطح درام

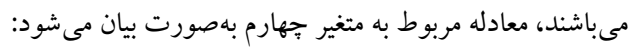

$e_{42} \frac{d p}{d t}+e_{43} \frac{d \alpha_{r}}{d t}+e_{44} \frac{d V_{s d}}{d t}=\frac{\rho_{s}}{T_{d}}\left(V_{s d}^{0}-V_{s d}\right)$ $+\frac{h_{f}-h_{w}}{h_{c}} q_{f}$

كه ضرايب بهصورت زير بيان مىشوند.

$$
\begin{aligned}
e_{42}= & V_{s d} \frac{\partial \rho_{s}}{\partial p}+\frac{1}{h_{c}}\left(\rho_{s} V_{s d} \frac{\partial h_{s}}{\partial p}+\rho_{W} V_{W d} \frac{\partial h_{W}}{\partial p}-V_{s d}-V_{W d}+m_{d} C_{p} \frac{\partial t_{s}}{\partial p}\right) \\
& +\alpha_{r}(1+\beta) V_{r}\left(\bar{\alpha}_{V} \frac{\partial \rho_{s}}{\partial p}+\left(1-\bar{\alpha}_{V}\right) \frac{\partial \rho_{W}}{\partial p}+\left(\rho_{s}-\rho_{W}\right) \frac{\partial \bar{\alpha}_{V}}{\partial p}\right) \\
e_{43}= & \alpha_{r}(1+\beta)\left(\rho_{s}-\rho_{W}\right) V_{r} \frac{\partial \bar{\alpha}_{V}}{\partial \alpha_{r}}
\end{aligned}
$$

$e_{44}=\rho_{s}$

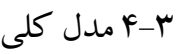

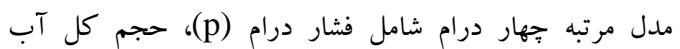

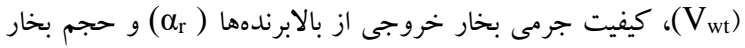

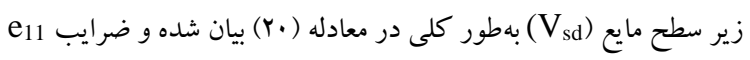
تا e eيز در معادله هاى (9)، (11) و (19) ارايه شده است.

$e_{11} \frac{d V_{w t}}{d t}+e_{12} \frac{d p}{d t}=q_{f}-q_{s}$

${ }^{1}$ Volume of the Steam in hypothetical situation 


\section{ع- ياسخ حلقه باز سيستم به ورودى يله}

براى نشان دادن رفتار غيرخطى درام بويلر نيرو كاه كرمان مى توان

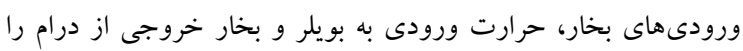

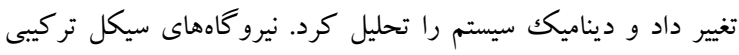

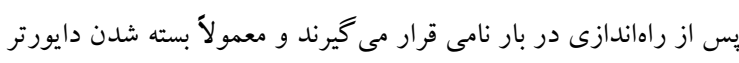

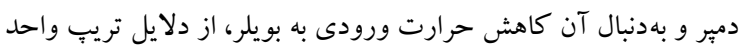

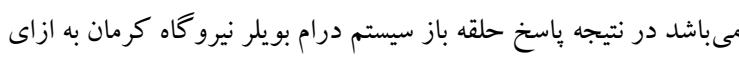

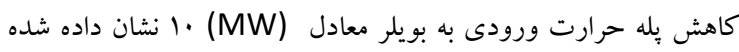

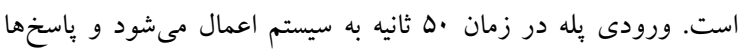

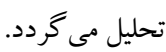

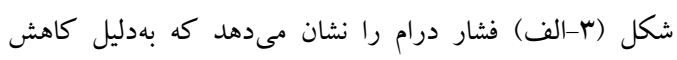

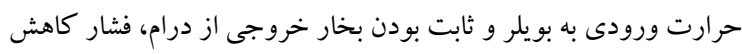

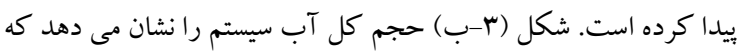

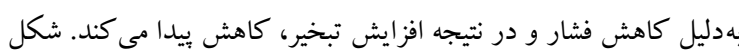

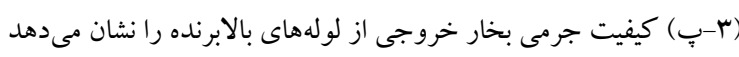

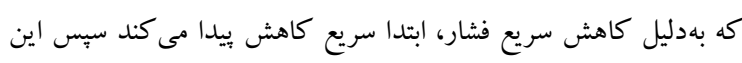

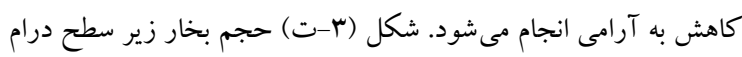

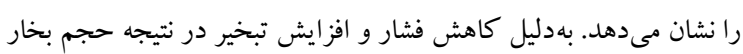

$$
\text { زير سطح درام افزايش ييدا مى كند. }
$$

شكل (r-ث) جريان جرمى لولههاى بالابرنده و بايين برنده رانشان

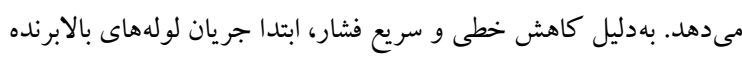

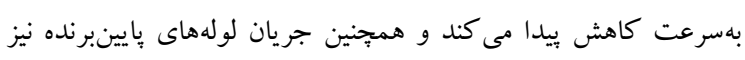

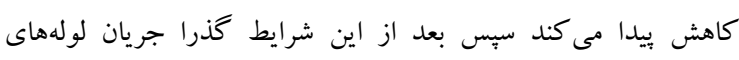

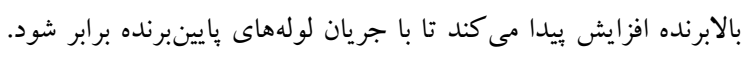

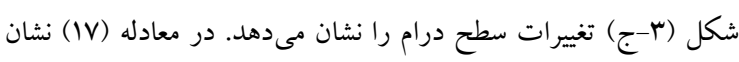

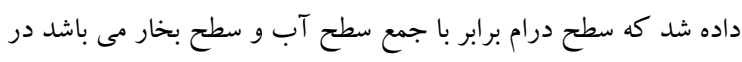

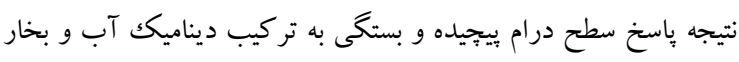

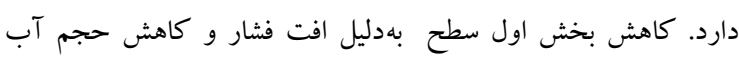

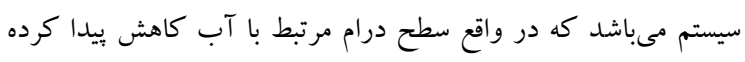

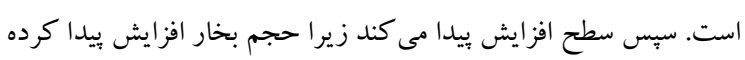

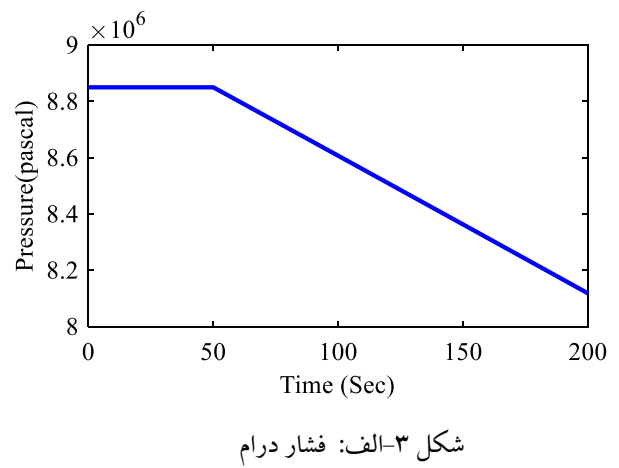

تغيير حرارت ورودى، تغييرات نسبت حجمى در بار بالا كمتر از زمانى

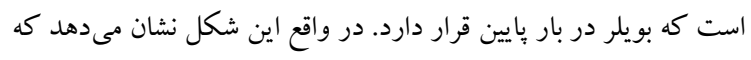

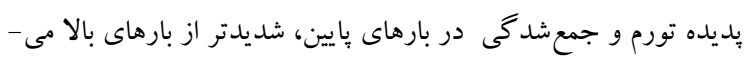

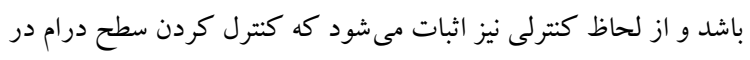

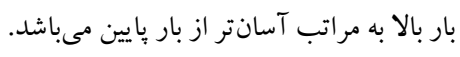

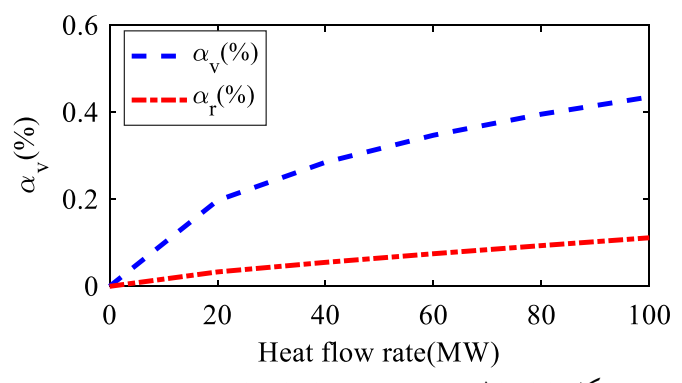

شكل r: ارتباط نسبت حجمى بخار با حرارت ورودى

$$
\text { r-9 شرايط اوليه سيستم }
$$

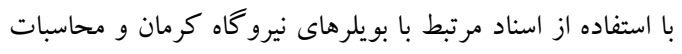

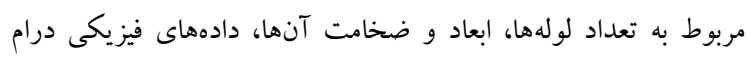

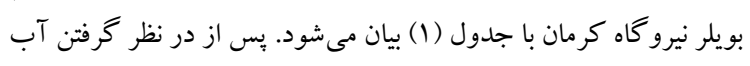

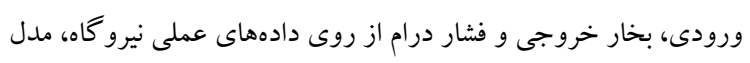

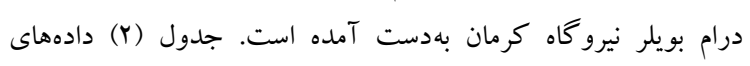

\begin{tabular}{|c|c|c|}
\hline 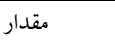 & واحد & كميت \\
\hline$r \cdot . r F$ & $\left(m^{3}\right)$ & حجم درام(V) \\
\hline rI. F & $\left(m^{3}\right)$ & حجم لو لههاى بالابرنده(Vr) \\
\hline 9.09 & $\left(\mathrm{~m}^{3}\right)$ & حجم لو لههاى يايين برنده (Vdc) \\
\hline $994 .$. & $(\mathrm{kg})$ & وزن درام(md) \\
\hline Q৭YYV.rY & (kg) & وزن لولههاى بالابرنده (mr) \\
\hline INAVGF.YG & (kg) & وزن كل(mt) \\
\hline$\cdot .11 \mathrm{VA}$ & $\left(m^{2}\right)$ & سطح مقطع لوله پايينبرنده (Adc) \\
\hline
\end{tabular}
ورودى و مقادير حالت تعادل درام بويلر را نشان مىدهد.

\begin{tabular}{|c|c|c|}
\hline مقدار & واحد & كميت \\
\hline 4. & $(\mathrm{~kg} / \mathrm{s})$ & آب وروددى (quf \\
\hline 4. & $(\mathrm{~kg} / \mathrm{s})$ & بخار خروجى (qs) \\
\hline$\wedge . \Delta \mathrm{V}$ & $(\mathrm{MW})$ & حرارت ورودى(Q) \\
\hline$\Lambda . \Delta$ & Bar & فار درام (P) \\
\hline 0.9 & $\mathrm{~m}^{3}$ & حجم بخار زير سطح (Vsd) \\
\hline ra.11 & $\mathrm{m}^{3}$ & حجم كل آب (Vwt) \\
\hline$\cdot .1 \cdot r$ & - & كيفيت جرمى بخار ( $)$ \\
\hline
\end{tabular}


0- منطق فعلى كنترل سطح درام نيروگاه

كرمان

در [•1] كنترل تكك المانه براى سطح درام نيرو كاه بخار بررسى

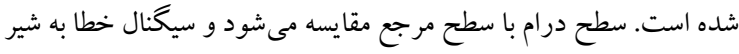

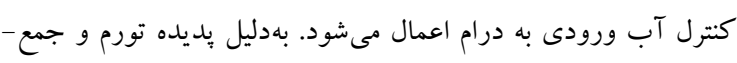

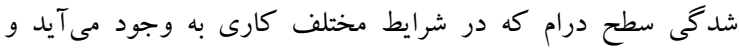

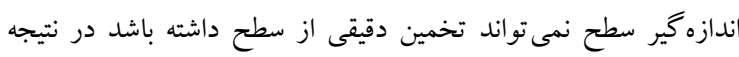

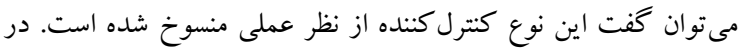

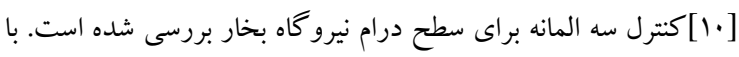

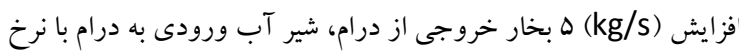

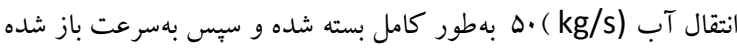

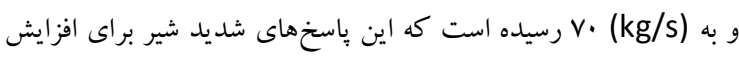
ه ه آب ورودى به درام جهت اصلاح سطح، هيج كونه توجيه (kg/s)

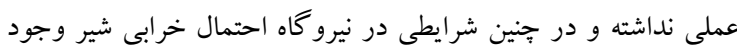

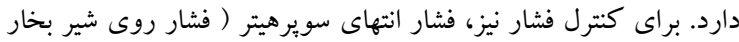

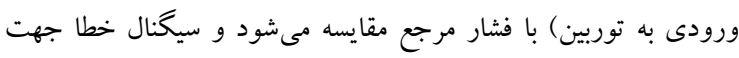
افزايش يا كاهش حرارت مشعلها جهت كنترل فشار انجام مىشود. در برد

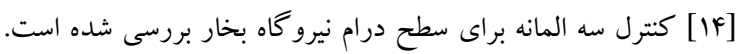

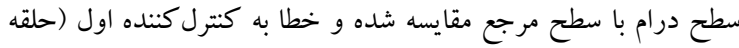

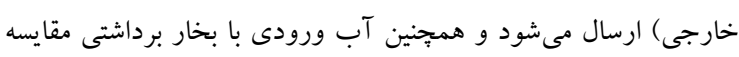

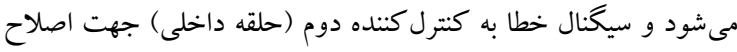

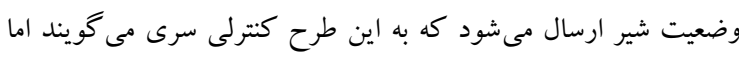

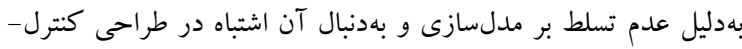

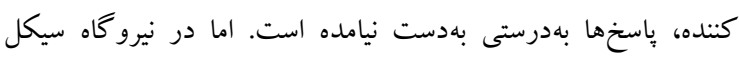

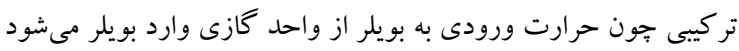

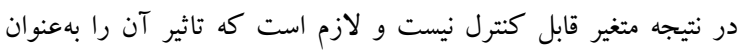

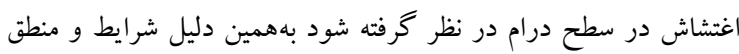

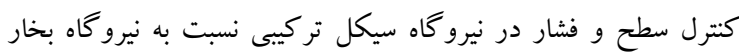

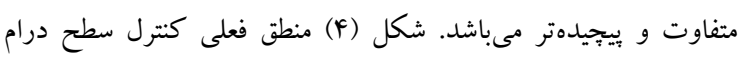
نيرو كاه سيكل تركيبى كرمان را نشان مىدهد. در اين منطق سيكال فئنال

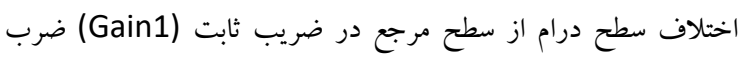

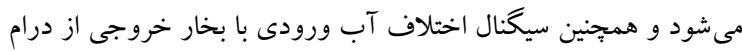

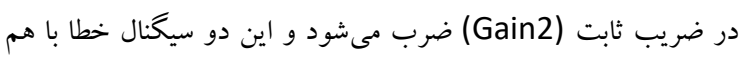

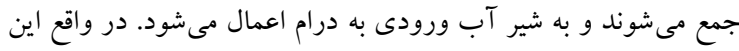

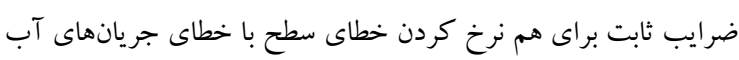
ورودى و بخار خروجى مىباشد. لازم به ذكر است كه از سيخنال فشار

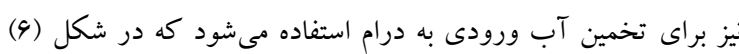

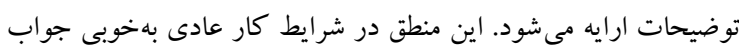

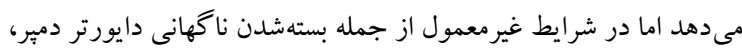
اختلال در شرايط دمايى بخار ورودى به توربين و غيره، نهتنها كنترل- دائل

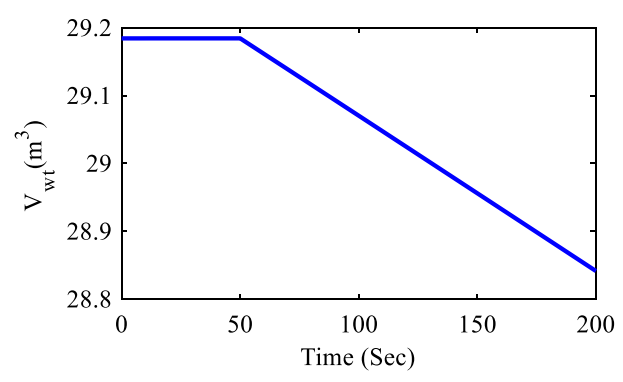

شكل r-ب: حجم كل آب

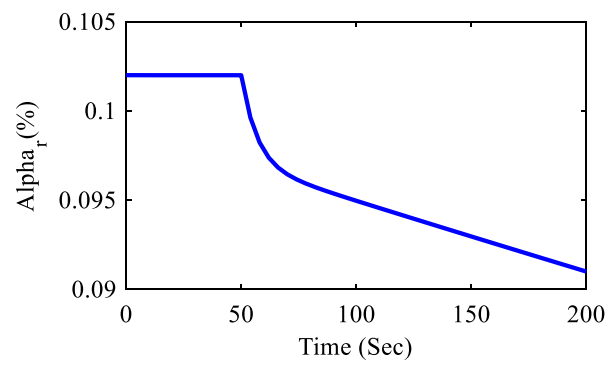

شكل r-ب: كيفيت جرمى بخار خروجى از لوله هاى بالابرنده

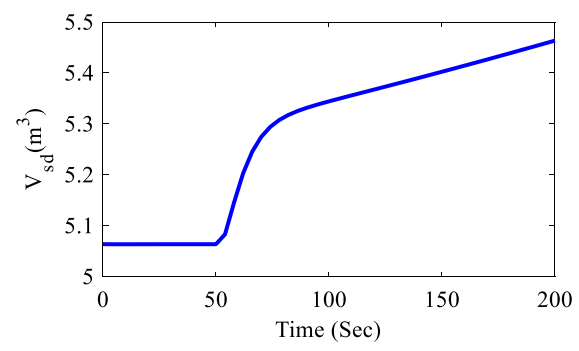

شكل r-ت: حجم بخار زير سطح درام

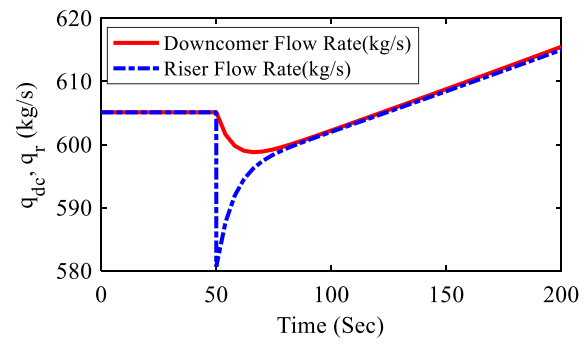

شكل r-ث: جريان لولههاى بالابرنده و يايينبرنده

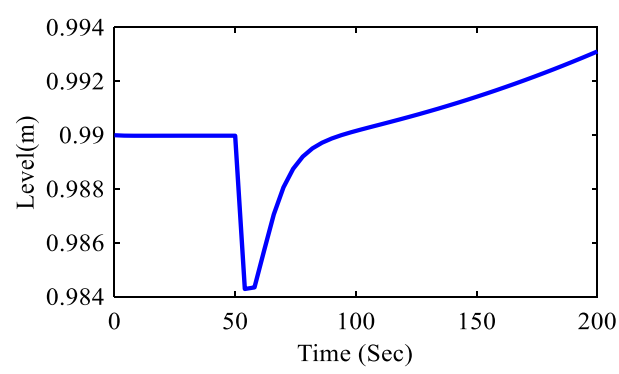

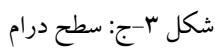

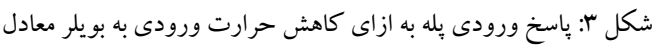

1. MW 
غيره جلو گيرى شود. تغييرات نرخ حرارت ورودى به بويلر و يا بسته شدن

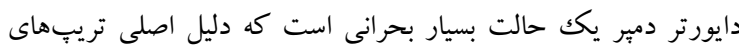

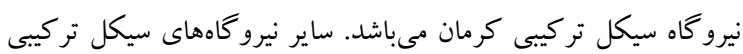

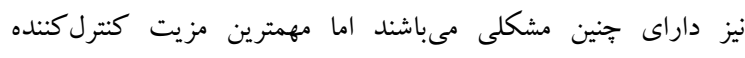

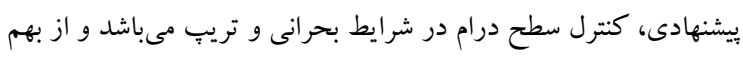

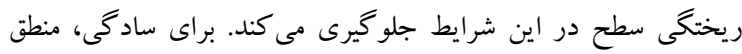

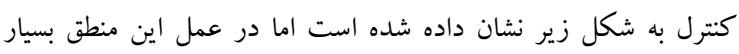

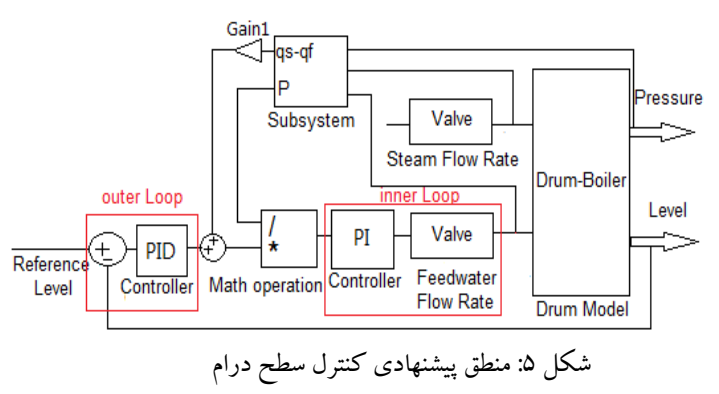

زير سيستم واقع در شكل (F و ها در شكل (q) نشان داده شده

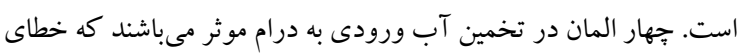
سطح درام در حلقه خارجى يكى از جهار المان مىباشد. سه المان ديخر

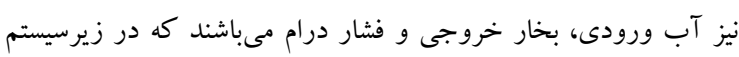

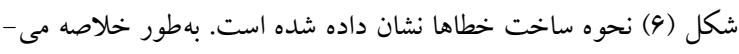

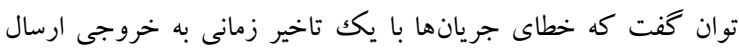

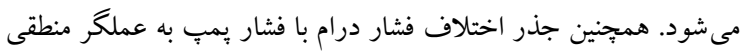

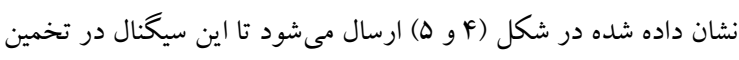

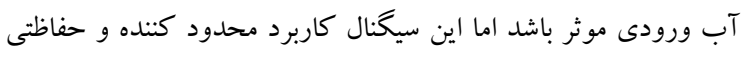

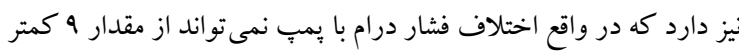

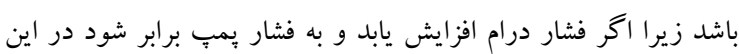
صورت آب ورودى درام صفر مى شود. لازم به ذكر است كه اعداد نشان داده شده در شكل (9) مربوط به درام فشار بالا مى باشد.

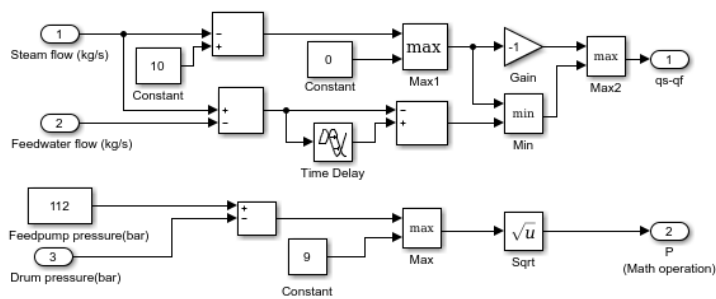

شكل 9: منطق ساخت سيگنال خطاى جريانها و فشار 9-1 طر احى كنترل كننده همانطور كه در بخش (ه) توضيحات ارايه در روش كنترل تكك المانه سطح درام با سطح مرجع مقايسه مى شود و سيگنال خطا جهت
كننده باسخ دقيقى نسبت به تغييرات سطح ندارد بلكه به نايايدار كردن

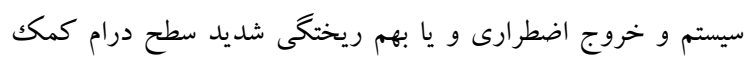

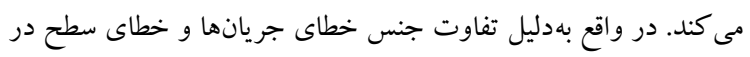
نتيجه كنترل كننده در شرايط غير معمول نمى تواند تخمين دقيقى از آب ورودى به درام جهت اصلاح سطح درام داشته باشد.

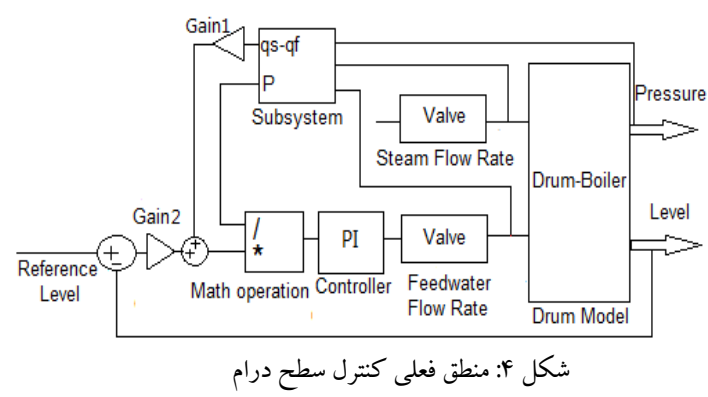

\section{7- منطق پيادهسازى شده براى كنترل سطح درام نيروكاه سيكل تركيبى كرمان}

شكل (ه) منطق جديد بيادهازى شده براى كنترل سطح درام

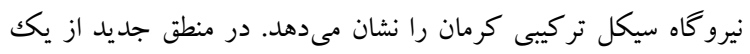

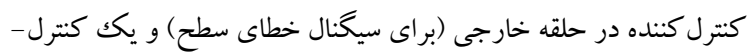

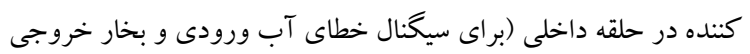

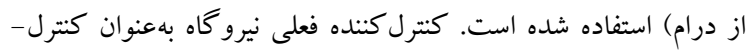

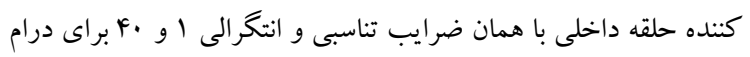

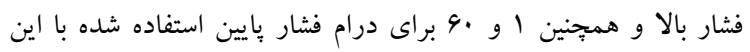
تفاوت كه در حلقه داخلى، ضريب ثابت براى خطاى جريانها (Gain1)

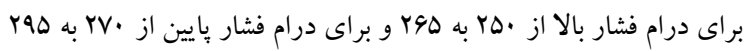

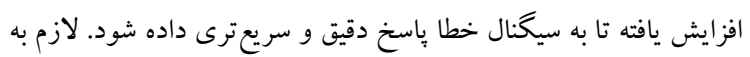
ذكر است كه خروجى كنترل كننده حلقه داخلى به شير ورودي دئ درام ارسال مىشود. در حلقه خارجى ضريب ثابت براى خطاى سطح (Gain2)

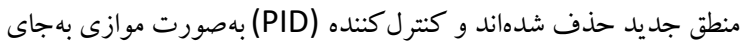

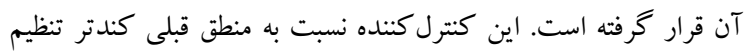
شده تا به نوسانهاى سطح باسخ سريع داده نشود زيرا سطح درام بهطور

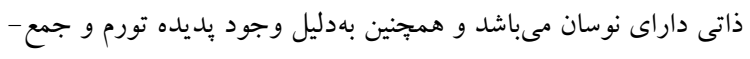

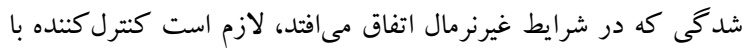

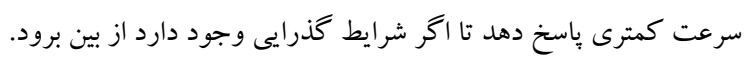

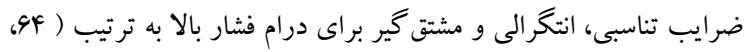

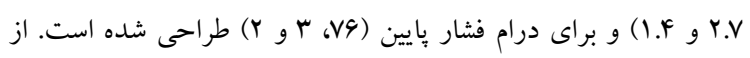
مزاياى اين منطق نسبت به حالت قبل مى توان به تنظيم مجزا كنترل كننده

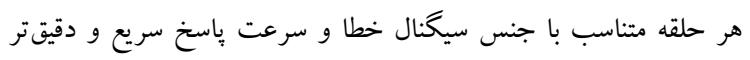

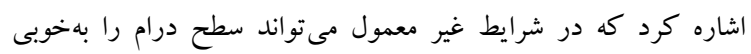

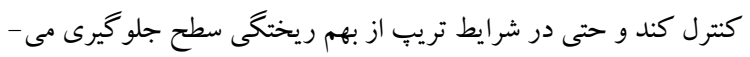

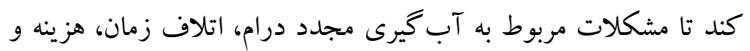


واحدكازى، دايورتر دمبر كاملاً بسته شده و منطق جديد

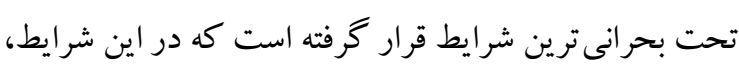

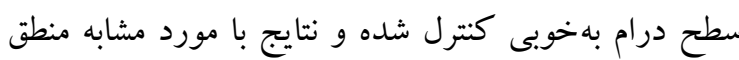
قبلى كه بجهم ريختىى سطح و خروج اضطرارى رخ داده، مقايسه شده

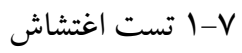

شكل (V) نتايج تست مقايسه كنترل فعلى و ييشنهادى سطح درام

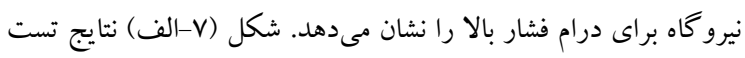

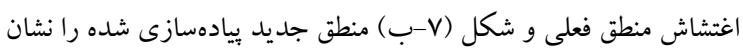

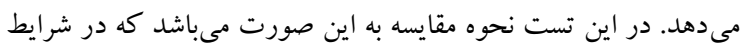

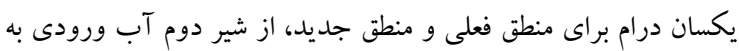

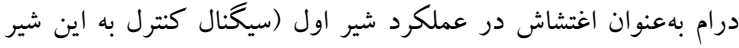

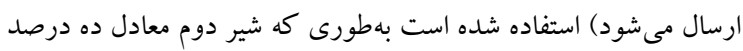

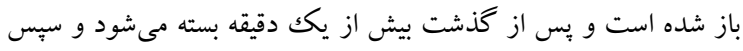

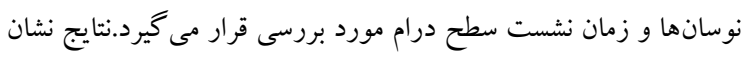

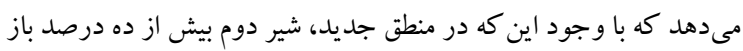

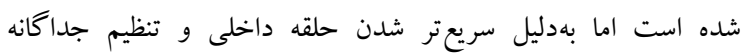

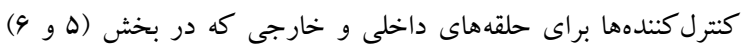

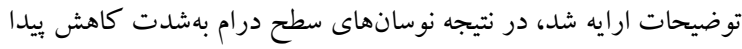

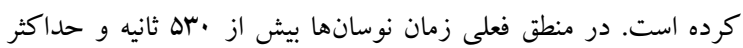

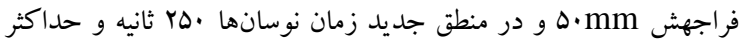

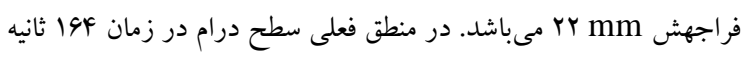

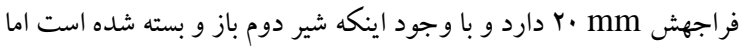

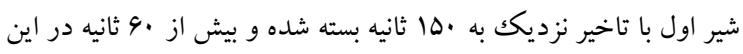

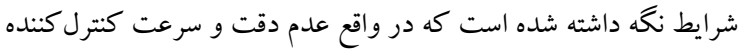

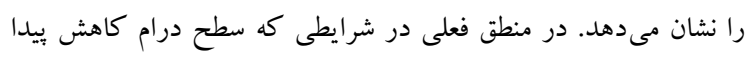

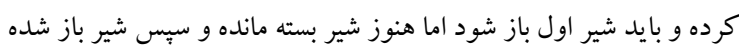

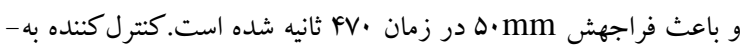

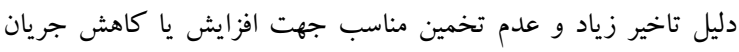

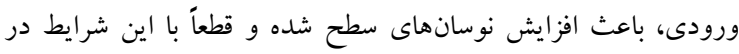

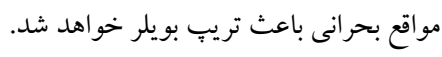

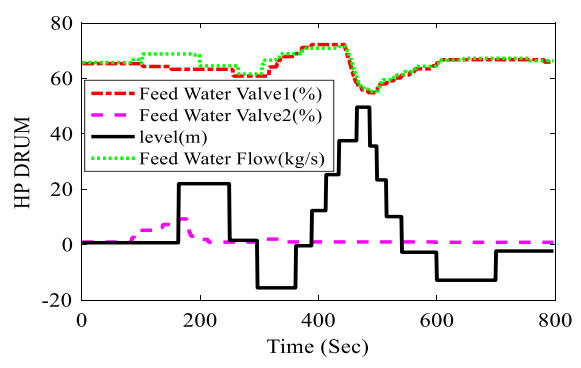

شكل v-الف: منطق كترل فعلى سطح درام
اصلاح سطح به شير آب ورودى درام ارسال مى شود. براى كنترل تكك

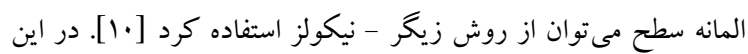

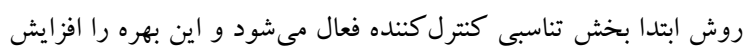

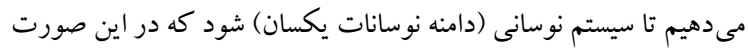
دامنه نوسانات بهره نوسانى و اختلاف زماند

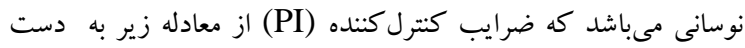

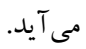

$$
\begin{aligned}
& K p=.45 K_{u} \\
& K i=1.2 K_{p} / p_{u}
\end{aligned}
$$

در نيرو گاههاى حرارتى به دليل وجود حلقه كنترل فشار مجزا لازم است كه ابتدا حلقه كتترل فشار سيس حلقه كنترل سطح تنظيم شود زير ديرا

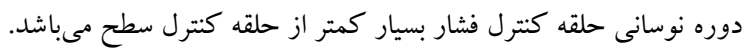

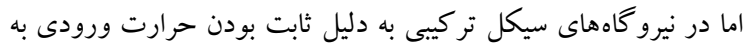

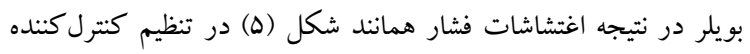

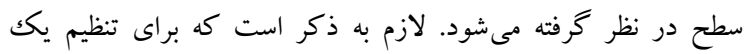

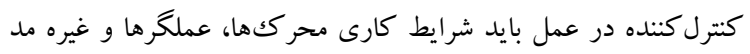

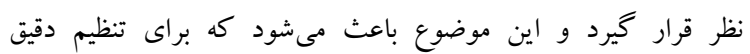

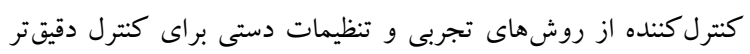

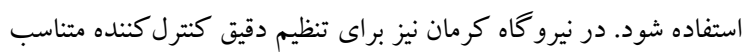

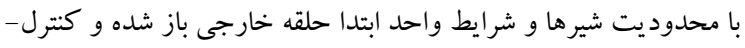

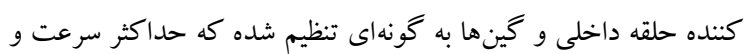
هاسخ دقيق را داشته باشد. سيس حلقه خارجى بسته شده و كنتر كنينده آن طورى تنظيم شده كه سرعت كمترى نسبت به حلقه داخلى دانلى داشته

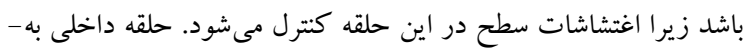

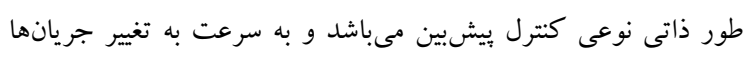

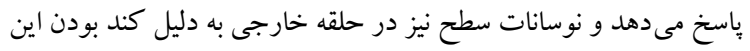

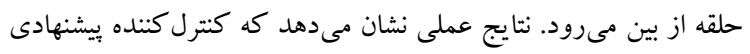
از خروجهاى اضطر ارى و بهم ريختخى سطح جلو كيرى مى كند.

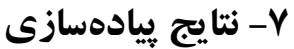

منطق جديد در واحد سوم بويلر نيرو گاه سيكل تركيبى

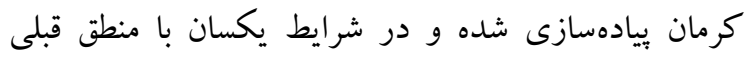
مقايسه شده است. تستهاى اوليه از جمله تست اغتشاش نشان دهنده بهبود كنترل سطح درام نسبت به حالت قبل مى باشد. بهدليل وجود محدوديت هاى نيرو كاهى و احتمال بروز مشكلات در اثر ايجاد مصنوعى تستهاى بحرانى در نتيجه

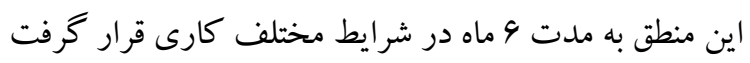

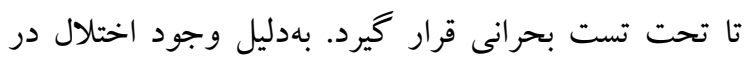


كمى سطح كاهش بيدا كرده و شير آب ورودى براى اين كاهش سطح

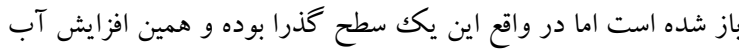

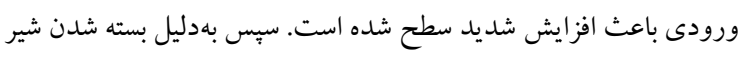

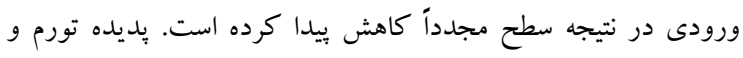

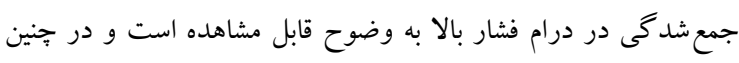

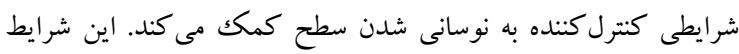

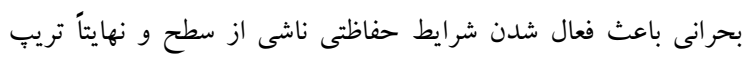

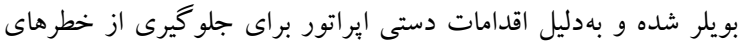

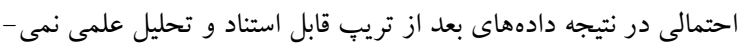

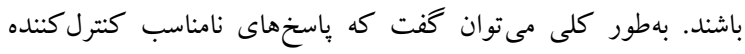
باعث نوسانى شدن شديد سطح و اخلال در عملكرد سيستم و نهايتاً فعال شدن شرايط حفاظتى و تريب واحد شده است. درام فشار بايين تقريباً

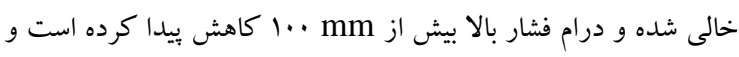

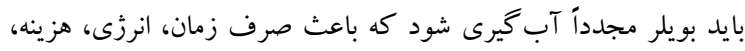
كاهش توليد و غيره مىشود.

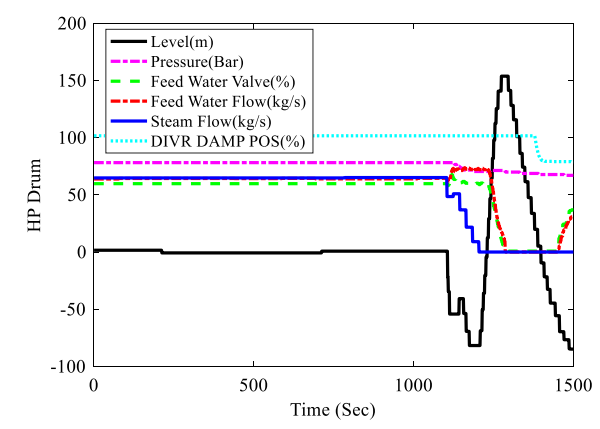

شكل ^-الف: درام فشار بالا

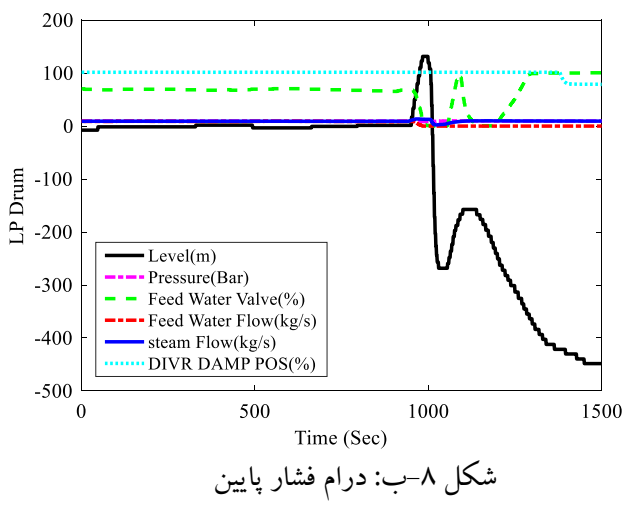

شكل ^: تست حالت بحرانى منطق فعلى كنترل سطح درام فشار پايين و فشار بالا نيرو گاه كرمان

شكل (9) نتايج منطق كنترل جديد بيادهسازى شده در نيرو كاه

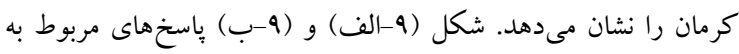

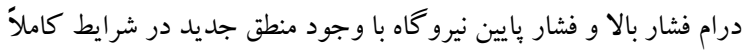

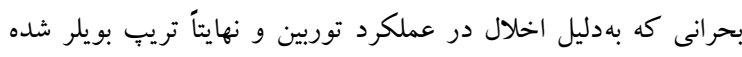

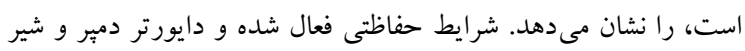

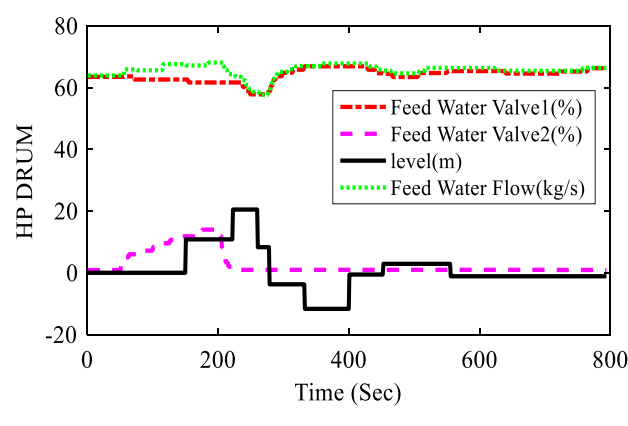

شكل V-ب: منطق كنترل ييشنهادى سطح درام

شكل V: مقايسه نتايج منطق كنترل فعلى و جديد سطح درام نيرو گاه

كرمان

$$
\text { Y-V }
$$

تغيير در حرارت ورودى به بويلر و بهدنبال آن تغيير در كيفيت

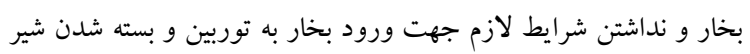

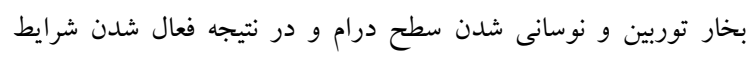

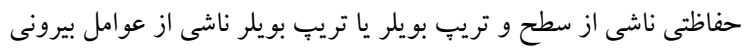

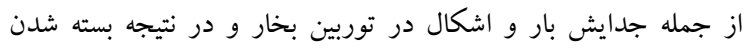

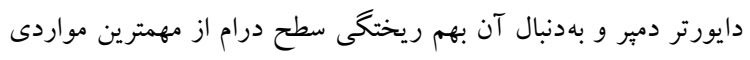

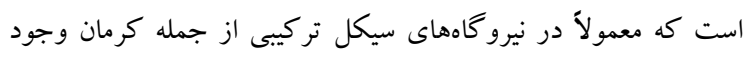

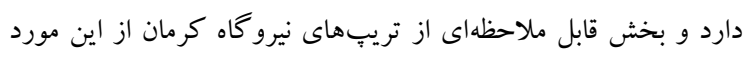

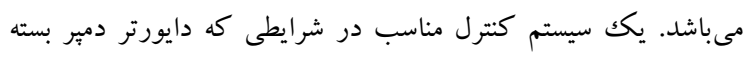

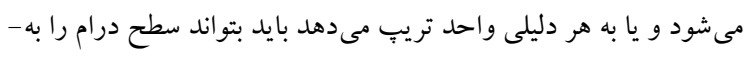

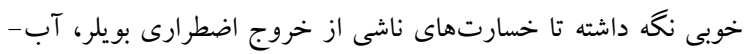

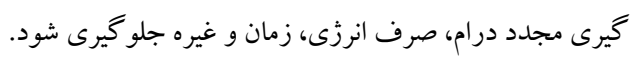

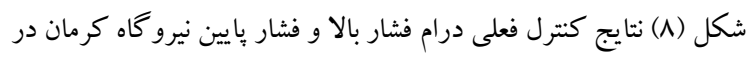

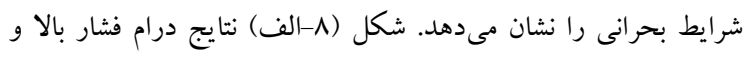

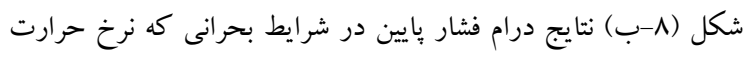

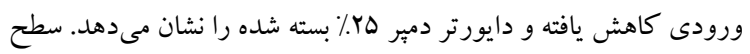

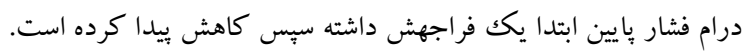

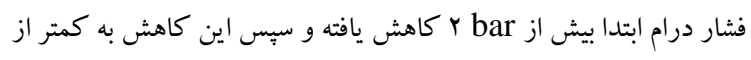

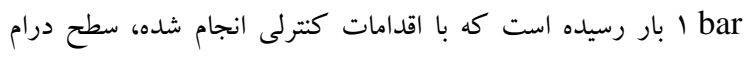

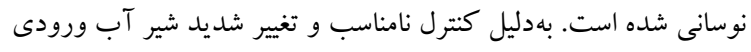

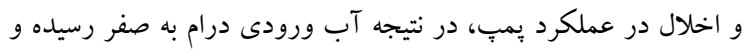

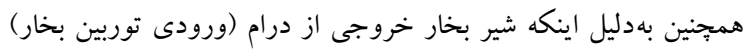

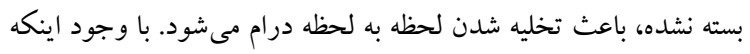

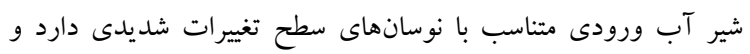

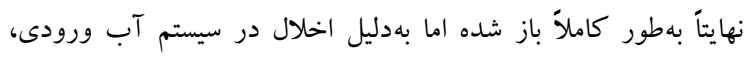

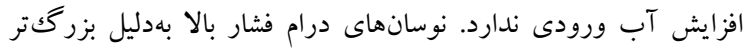

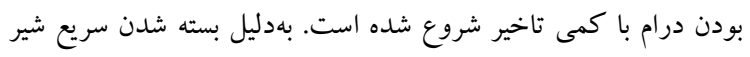
بخار خروجى از درام و كمى تاخير در كاهش فشار درام در نتيجه ابتدا 
شد. در بخش (9) اين نتيجه حاصل شد كه بهتر است از دو حلقه كنترل جهت تخمين آب ورودى به درام جهت اصلاح سطح استفاده شود تا بتوان در شرايط غير معمول و اغتشاش، سطح درام را كنترل نمود كه. نتايج بخش (V-1) اين موضوع را اثبات كرد. در بخش (V-Y) نيز نتايج نشان داد كه منطق جديد در شرايط بحرانى و تريب، از بهم ريختگى سطح جلو گيرى مى كند و سطح درام را در محدوده امن نكه مىدارد. لازم به ذكر است كه با توجه به ظهور شرايط بحرانى ديخرى كه روى واحدهاى با منطق كنترلى جديد اتفاق افتاده، يايدارى سيستم بارها محك خورده و مزيت اين روش نسبت به قبل بسيار مشهود است بهطورى كه برخى از تست هاى نايايدار ساز سيستم كه مصداق ورود اغتشاش و نامعينى به سيستم هستند و تا بيش از اين با دخالت انسانى قابليت انجام داشتند را در حال حاضر بهره بردار بدون دخالت انسانى و به اتكاى

\section{مراجع}

[1] Åström, K. J. and Bell, R. D. 2000. Drumboiler dynamics. Automatica, 36: 363-378.

[2] Kim, H. and Choi, S. 2005. A model on water level dynamics in natural circulation drum-type boilers. International Communications in Heat and Mass Transfer, 32: 786 -796.

[3] Lu, S. and Hogg, B. 2000. Dynamic nonlinear modelling of power plant by physical principles and neural networks. International Journal of Electrical Power \& Energy Systems, 22: 67-78.

[4] Fan, H., Zhang, Y. F., Su, Z. G., Wang, B. 2017. A dynamic mathematical model of an ultra-supercritical coal fired once-through boiler-turbine unit. Applied Energy, 189: 654-666.

[5] Moradi, H., Saffar-Avval, M. and Bakhtiari-Nejad, F. 2012. Sliding mode control of drum water level in an industrial boiler unit with time varying parameters: A comparison with Ho-robust control approach. Journal of Process Control, 22: $1844-1855$.

[6] Li,L. and Ding, W. 2016. Optimization control strategy of boiler water level based on fuzzy PID. Control and Decision Conference (CCDC), Chinese.IEEE. 58935896.

[7] Sheng, L., Shiquan, Z. and Yuchao, W.2015. Sliding mode controller with AGA for drum water level of ship boiler.
بخار ورودى توربين كاملاً بسته شده و سطح درام نيز هر لحظه در حال

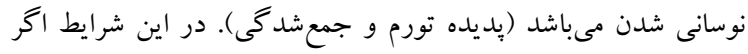

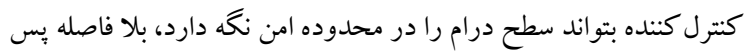

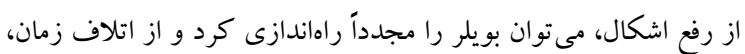
انرزى، كاهش توليد و خسارتهاى ديخر جلو گيرى كرد. بهان بهدنبال بسته شدن شير بخار، شير آب ورودى بهسرعت بسته شده است (حلقه داخلى).

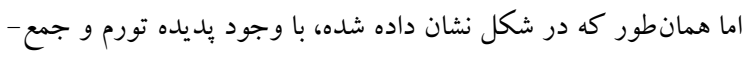
شدگى شديد، كنترل كنده به اين نوسانها واكنش كندى نشان مى دهدان

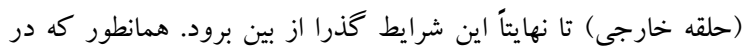

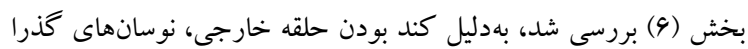

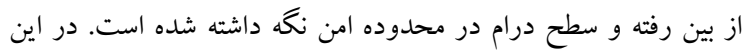

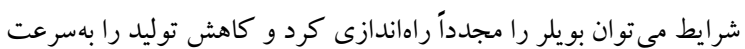

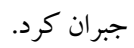
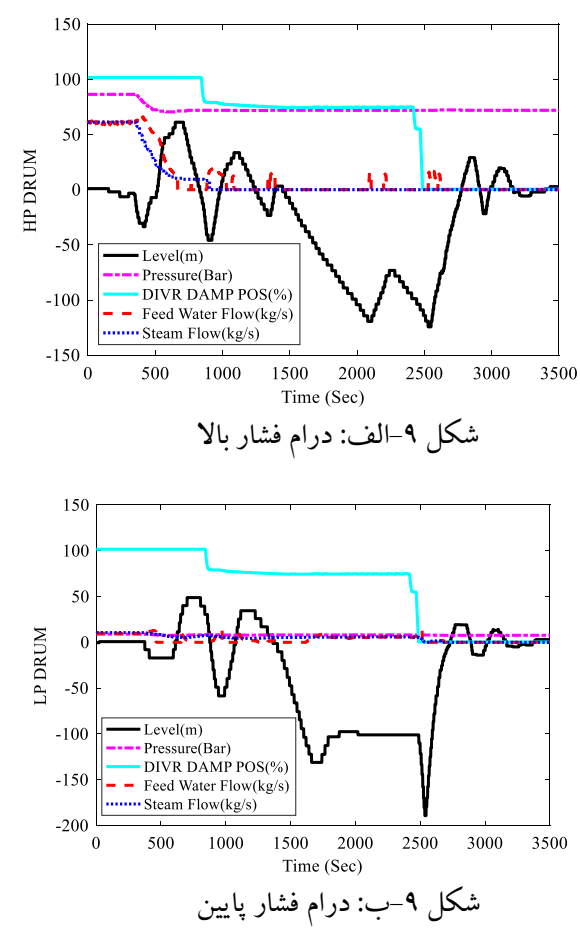

شكل 9: نتايج منطق جديد كنترل سطح درام نيرو كاه

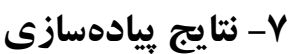

در اين مقاله ابتد درام بويلر نيرو كاه سيكل تركيبى كرمان مدلسازى شده و بس از تحليل رفتار ديناميك اساسى سيسم، در بخش (r-هاه)

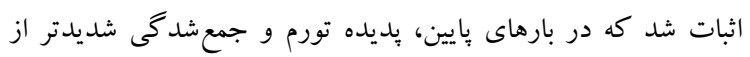
بارهاى بالا مىباشد و براى اينكه كنترل سطح درام راحتتر انجام شود بايد بويلر در بار نامى خود قرار داشته باشد. در بخش (ه) توضيحاتى در مورد روشهاى كنترلى نيرو كاه بخار و منطق فعلى كنترل سطح درام ارايه 


\section{Control Conference (CCC), 34th} Chinese.IEEE. 3116-3120.

[8] Alaei, H. J. and Yazdizadeh, A. 2016. A new robust $\mathrm{H} \infty$ sliding mode observerbased state estimation and fault reconstruction for nonlinear uncertain boiler system. Soft Computing. 21: 39573968.

[9] Aliakbari, S., Ayati, M., Osman, J. H. and Sam, Y. M. 2013. Second-order sliding mode fault-tolerant control of heat recovery steam generator boiler in combined cycle power plants. Applied Thermal Engineering, 50: 1326-1338.

[10] Alvandi M, Fadaee A. 2010. Nonlinear Modeling and PID Control System Design for a Typical Drum Steam Generator. $J o C$, 4 (2):66 -79.

[11] Åström, K. J. and Eklund, K. 1972. A simplified non-linear model of a drum boiler-turbine unit. International Journal of Control, 16: 145-169.

[12] Åström, K. and Eklund, K. 1975. A simple non-linear drum boiler model. International Journal of Control, 22: 739 740.

[13] Åström, K. J. and Bell, R. D. 1996. A fourth order non-linear model for drumboiler dynamics. In IFAC '96, Preprints 13th World Congress of IFAC, San Francisco, 13: 31-36.

[14] Lacob, M., Andreescu, G.D. 2011. Drumboiler control system employing shrink and swell effect remission in thermal power plants. Ultra Modern Telecommunications and Control Systems and Workshops (ICUMT),3rd International Congress on IEEE, 1-8. 